\title{
LATEST DEVELOPMENTS OF THE ISPRS STUDENT CONSORTIUM
}

\author{
I. Detchev ${ }^{\text {a, }}$, U. Kanjir ${ }^{\text {b }}$, S. R. Reyes ${ }^{\text {c }}$, H. Miyazaki ${ }^{\text {d }}$, A. F. Aktas ${ }^{\text {e }}$ \\ ${ }^{a}$ Dep't of Geomatics Engineering, University of Calgary, Alberta, Canada T2N 1N4 - i.detchev@ucalgary.ca \\ b Dep't of Remote Sensing, ZRC SAZU, Novi trg 2, 1000 Ljubljana, Slovenia - ursa.kanjir@zrc-sazu.si \\ ${ }^{c}$ Dep’t of Geodetic Engineering, University of the Philippines Diliman, Philippines - sherylrose.reyes@gmail.com \\ ${ }^{\mathrm{d}}$ Center for Spatial Information Science, University of Tokyo, Japan - heromiya@csis.u-tokyo.ac.jp \\ ${ }^{\mathrm{e}}$ Informatics Institute, Istanbul Technical University, 34469 Maslak - Istanbul, Turkey - akkartala@itu.edu.tr
}

\section{Commission VI, WG VI/5}

KEY WORDS: education, student network, young professionals, student events and activities, summer schools, newsletter, website

\begin{abstract}
:
The International Society for Photogrammetry and Remote Sensing (ISPRS) Student Consortium (SC) is a network for young professionals studying or working within the fields of photogrammetry, remote sensing, Geographical Information Systems (GIS), and other related geo-spatial sciences. The main goal of the network is to provide means for information exchange for its young members and thus help promote and integrate youth into the ISPRS. Over the past four years the Student Consortium has successfully continued to fulfil its mission in both formal and informal ways. The formal means of communication of the SC are its website, newsletter, e-mail announcements and summer schools, while its informal ones are multiple social media outlets and various social activities during student related events. The newsletter is published every three to four months and provides both technical and experiential content relevant for the young people in the ISPRS. The SC has been in charge or at least has helped with organizing one or more summer schools every year. The organization's e-mail list has over 1,100 subscribers, its website hosts over 1,300 members from 100 countries across the entire globe, and its public Facebook group currently has over 4,500 joined visitors, who connect among one another and share information relevant for their professional careers. These numbers show that the Student Consortium has grown into a significant online-united community. The paper will present the organization's on-going and past activities for the last four years, its current priorities and a strategic plan and aspirations for the future four-year period.
\end{abstract}

\section{INTRODUCTION}

The Student Consortium or SC is a well-accepted youth organization that functions under the umbrella of the International Society for Photogrammetry and Remote Sensing (ISPRS). It was established in 2004 at the ISPRS Congress in Istanbul, Turkey. The organization functions as a professional network for the exchange of information and creates opportunities for young researches to develop their career within the fields of photogrammetry, remote sensing, Geographical Information Systems (GIS), and other related geospatial sciences. The main goal of the Student Consortium is to organize student-specific events and to engage its members online so that students and youth are more effectively integrated into the ISPRS.

In 2008, at the ISPRS Congress in Beijing, China, the first board members were elected (Kanjir et al., 2014). The SC board represents the head of the organization. It is responsible for the management and administration of the society, the provision of support and communication between its members, and the maintenance of public relations and the active promotion of the ISPRS within the community.

This paper presents the activities during the mandate of the current SC board, which was elected at the ISPRS Congress in Melbourne, Australia in 2012. The main goal for the last four years was to encourage and continue to build a strong international community of young professionals in the field. The fact that the SC has continued to expand internationally can be seen through its membership growth, global summer school coverage, active presence in social media and the cultural variety of articles published in the Student Consortium Newsletter.

\section{SCALE OF STUDENT CONSORTIUM INVOLVEMENT}

The ISPRS Student Consortium (SC) currently encompasses more than 1387 members from 100 countries across the entire world (see Figure 1). The membership has almost doubled since the beginning of the current mandate in 2012 (see Table 1).

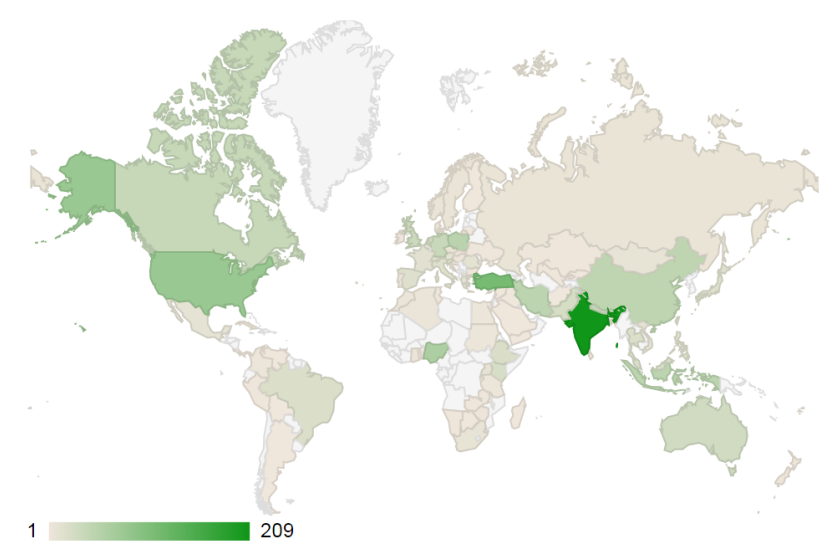

Figure 1. Membership density map.

\footnotetext{
* Corresponding author
} 
All undergraduate or advanced diploma students, and young researchers enrolled in Master's or doctoral degrees in an ISPRS-related field can join the organization by entering some basic information on the SC website: http://www.isprs-sc.org. Note that the ISPRS SC membership is free of charge.

\begin{tabular}{|c|c|c|}
\hline Year & No. of members & $\begin{array}{c}\text { No. of countries } \\
\text { with members }\end{array}$ \\
\hline 2010 & 380 & 68 \\
\hline 2012 & 750 & 85 \\
\hline 2014 & 1,100 & 93 \\
\hline 2016 & 1,390 & 100 \\
\hline
\end{tabular}

Table 1. Student Consortium membership growth.

The number of members frequently increases after summer schools, where participants connect with the SC board members in person and get informed about the organization and the team (Kanjir et al., 2014).

Note that the first SC board members were Europe centred (e.g., Turkey, Slovenia and Poland), and originally a large percentage of the SC membership was in Europe (see Figure 2, Figure 3, and Figure 6). Later on, there was an increase of interest in the $\mathrm{SC}$ in Asian countries and consequently both the overall membership and its representation on the second board (now from Turkey, Slovenia, Taiwan, Japan, the Philippines and Canada) reflected that (see Figure 2, Figure 4, Figure 5, and Figure 7).

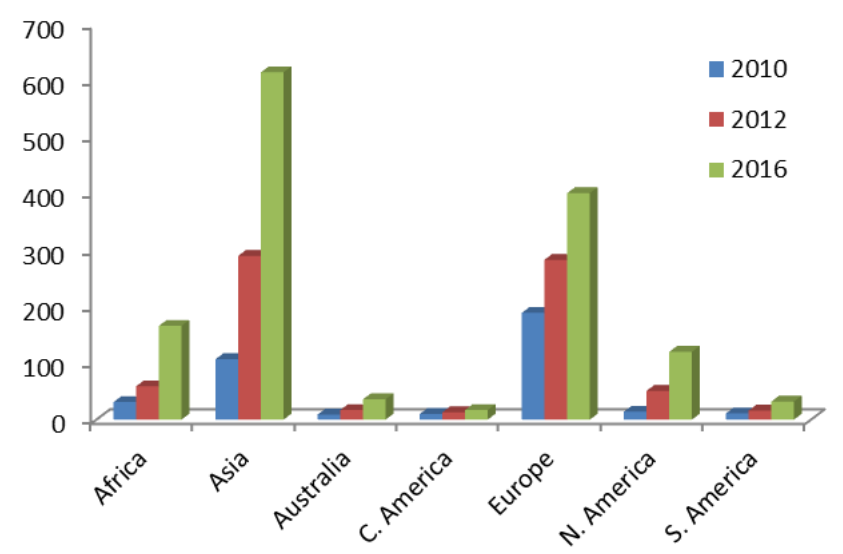

Figure 2. Number of members by geographical region.

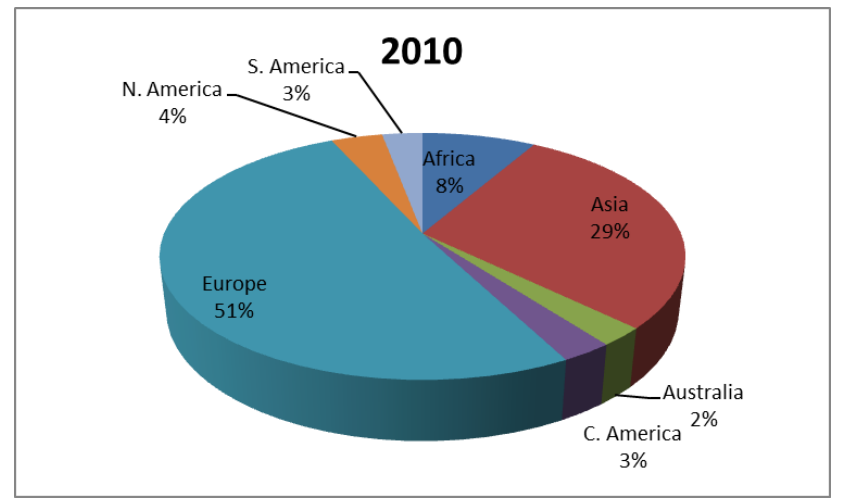

Figure 3. Percentage of members by geographical region for 2010 (Kivilcim et al., 2010).

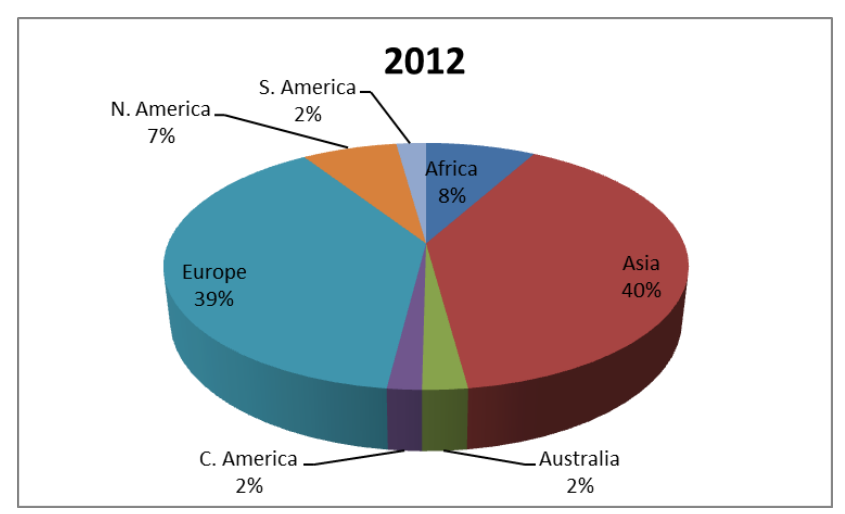

Figure 4. Percentage of members by geographical region for 2012 (Kivilcim et al., 2012).

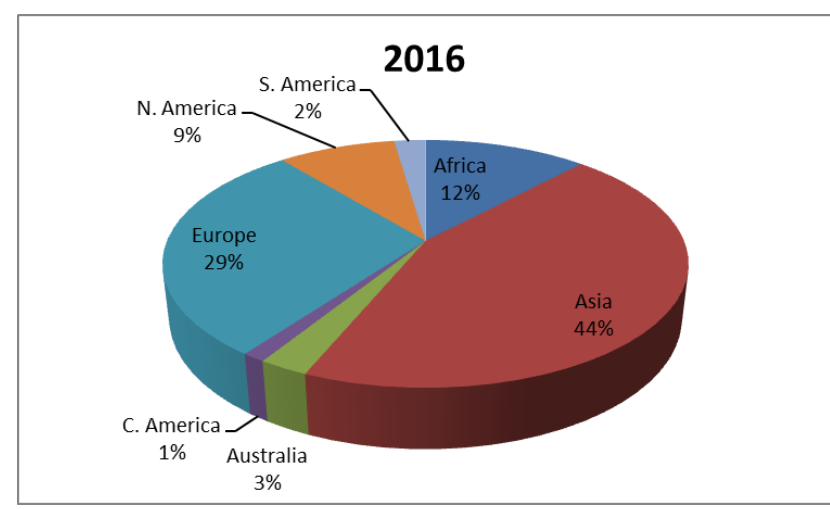

Figure 5. Percentage of members by geographical region for 2016.

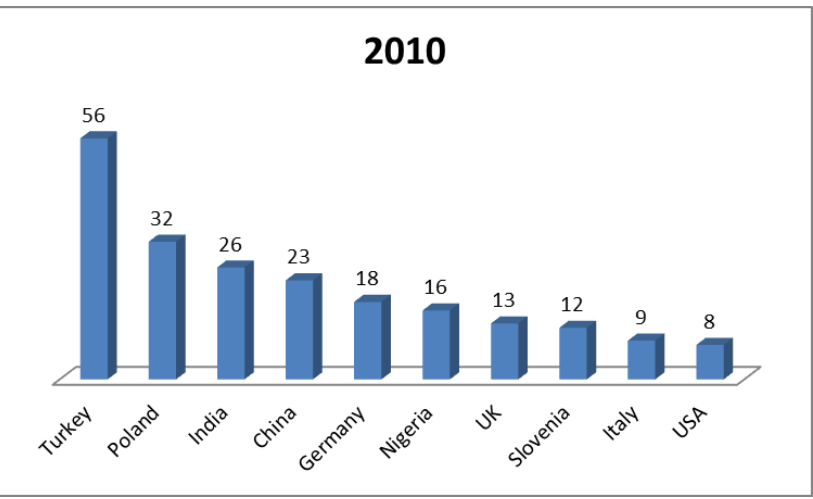

Figure 6. Top ten countries with the highest number of members in 2010 (Kivilcim et al., 2010).

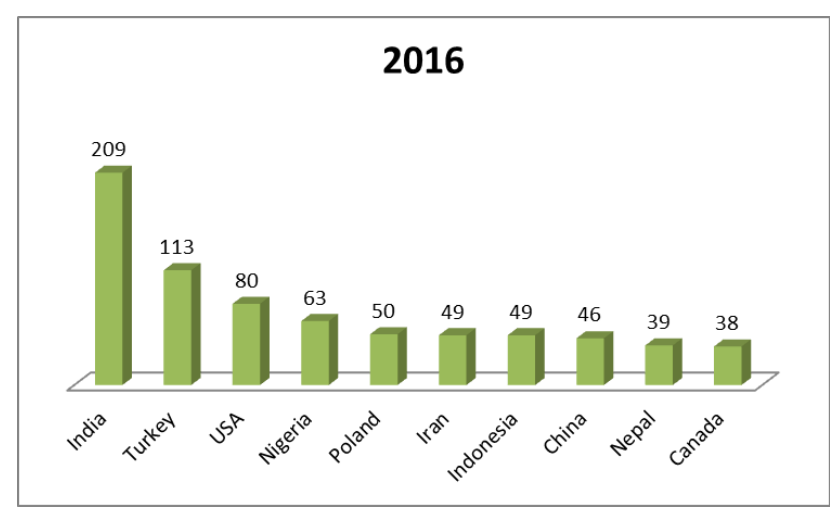

Figure 7. Top ten countries with the highest number of members in 2016. 


\section{STUDENT CONSORTIUM FUNCTIONS}

The SC activities throughout the last four years are presented next. The following subsections describe the summer schools, congress events, newsletter publications, website, and social media outreach of the society.

\subsection{Summer schools}

The SC has continued organising summer schools in different countries in coordination with local institutions. For the past four years, five summer schools were hosted in Asia and one in in Africa.

The cooperation and collaboration with the Asian Association on Remote Sensing (AARS) and its corresponding student organization, the AARS Student Group (ASG), organized four out of the five summer schools in Asia. These summer schools were hosted right after the annual Asian Conference on Remote Sensing (ACRS).

In 2012, the summer school was hosted at Burapha University, Chonburi, Thailand and was organised in coordination with the Geo-Informatics and Space Technology Development Agency (GISTDA) of Thailand. The lectures focused on topics about coastal zone monitoring and disaster management. In 2013, the summer school was held in Bali, Indonesia and the theme concentrated on the use of remote sensing for environmental monitoring. In 2014, the summer school was hosted by the University of Forestry in Yezin, Nay Pyi Taw, Myanmar (see Figure 8). This was the first summer school whose topics were dedicated primarily on the use of remote sensing and geospatial technologies in forestry and other related applications. The Department of Geodetic Engineering and the Institute of Environmental Science and Meteorology of the University of the Philippines - Diliman, hosted the most recent summer school in Asia in 2015 (see Figure 9). The use of various geospatial tools and technologies for natural resources management were the focus of the discussions and practical exercises.

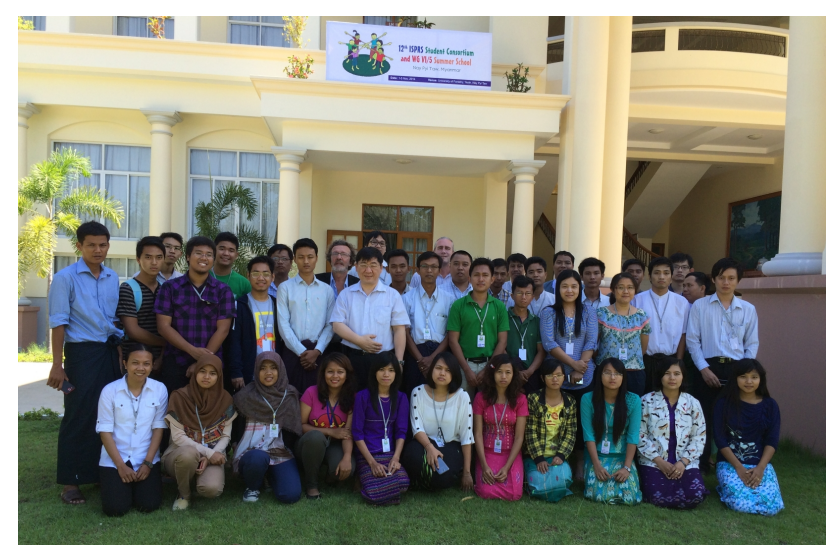

Figure 8. Group photo at the 2014 Myanmar summer school.

Apart from the ACRS, two additional summer schools were organised. The first one occurred in Addis Ababa, Ethiopia in 2013 as a response of the SC to the growing need for further knowledge and education in remote sensing and other geospatial sciences in this country. This was an important summer school for the SC since it signified the expanding reach of the organization. As stated by Dowman and Kufoniyi (2010), Africa is an important region because of the opportunities in delivering new knowledge, contributing to the continent's development and integrating Africans to the activities of ISPRS. Through the assistance of local authorities in 2013 at the UN Economic Commission for Africa (UNECA) Headquarters in Addis Ababa, this summer school was able to accommodate participants from six African countries, namely Rwanda, Uganda, Tanzania, Ethiopia, Nigeria, and Kenya.

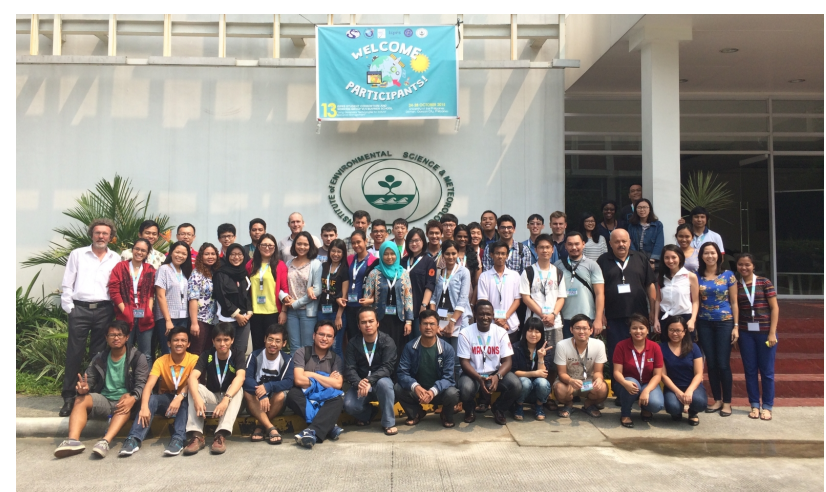

Figure 9. Group photo at the 2015 summer school in the Philippines.

The other summer school was held in Wuhan, Hubei, China in 2014 (see Figure 10). This was a major event for the working groups within the ISPRS Technical Commission VI (Education, Technology Transfer and Capacity Development) and an integration of a number of activities specifically organised for students and young researchers. The organization of the summer school was led by Wuhan University, the State Key Laboratory of Information Engineering in Surveying, Mapping and Remote Sensing (LIESMARS) in coordination with ISPRS Student Consortium, and working groups WG VI/4, WG VI/5 and WG VI/6 within the ISPRS Technical Commission VI. This summer school was held as part of the activities of the ISPRS Technical Commission VI Mid-Term Symposium with the theme, "Data, Information and Knowledge Sharing for Geo-Education." This summer school was integrated with the 2014 Geoinformatics Summer Camp and another ISPRS student-oriented activity the 5th ISPRS $3 \mathrm{~S}$ - Summer Students Seminar.

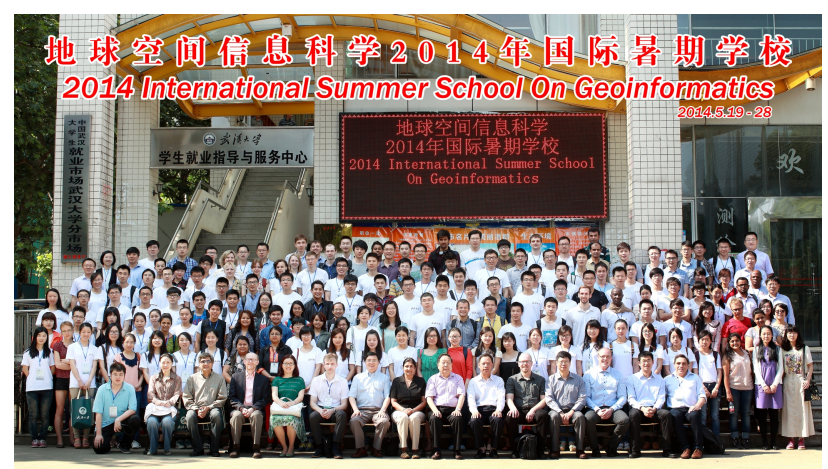

Figure 10. Group photo at the 2014 summer school in Wuhan, China.

In the last four years, there was an overwhelming response to participate in the summer schools. Most of these summer schools hosted about 40 to 60 participants, comprised of both foreigners and locals. In addition, the current design of the summer school proves to be an effective and efficient way of educating the participants in the latest advancements in remote sensing and geospatial sciences. The themes cover general or specific topics, the technical tours provide further knowledge on actual applications of remote sensing, and the social events 
foster relationships among the participants. The locations of the $\mathrm{SC}$ summer schools in the last four years are summarized in Table 2 .

\begin{tabular}{|c|c|}
\hline Year & Location \\
\hline 2012 & Pattaya, Thailand \\
\hline \multirow{2}{*}{2013} & Bali, Indonesia \\
\cline { 2 - 2 } & Addis Ababa, Ethiopia \\
\hline \multirow{2}{*}{2014} & Nay Pyi Taw, Myanmar \\
\cline { 2 - 2 } 2015 & Wuhan, China \\
\hline
\end{tabular}

Table 2. Summary of the locations of the last six SC summer schools.

In addition, a Student Consortium summer school will take place in Telč, Czech Republic in early July, 2016. Potentially, there also will be a summer school organized in conjunction with the 2016 ACRS in Sri Lanka.

\subsection{Congress events}

The SC takes an active role at each ISPRS congress by organising variety of youth-specific events during the events. The goal is to do the same for the 2016 ISPRS Congress, which will take place in Prague, the Czech Republic in July 2016. An entire day during the conference will be aimed at the young people in the SC. Namely, an event referred to as the Youth Forum will take place on Sunday, July 17. Youth forums are special sessions during ISPRS congresses that are dedicated to students and have been established by ISPRS since the 1990s and early 2000s (Baltsavias, 2005). Young authors can have the chance to publish their work and present it in front of their peers. Papers accepted after an abstract or a full paper peer review will be presented orally or in a form of an interactive poster. Three oral sessions with five presenters each will be organized during the 2016 Youth Forum. The full text of these papers will be published in a special volume of the congress proceedings. After the technical sessions, a panel discussion will take place. This public debate with the title "Industry/company or academia/science - where do I fit in after graduation?" will combine aspects from three speakers, each coming from the three different branches of the economy: the academic, private and public sectors. Last but not least, there will be a general assembly, where the new board members will be elected and any changes to the SC statutes will be voted on.

\subsection{Newsletter publications}

ISPRS Student Consortium began publishing the SC Newsletter with the collaboration of students and young professionals aiming to announce $\mathrm{SC}$ activities and release interesting articles and interviews related to the society starting from 2007 onwards (Kivilcim, 2008). Through its broadcasting life so far the SC Newsletter has fulfilled the needs of the Student Consortium's expanding and various members while gaining more attention and raising awareness. It is attempted that the newsletter is attractive in content and design in order to be noticed, and to create a positive image with the young readers. In this time frame, some sections such as career building, student exchange experience articles, more technical articles from student studies were added among regular sections which are interviews by academics, articles from students, regular columns, etc.

The SC Newsletter requires continuous activity, and the SC board and regular members collaborate from the brainstorming to the distribution phase, under the coordination of the editor-inchief. In the last four-year period, 57 different contributors from various countries submitted content base to the SC Newsletter either on a regular or a one-time basis. All contributions submitted to the newsletter are published online and are under the creative commons license. This could be considered a contribution on its own as simply distributing articles through social media and e-mail channels was not a viable option. Both the contributors and the SC board members put in a lot of effort in writing, collecting, editing, designing and typesetting the articles, so publishing under a license was essential in order for all the work to be protected.

Since 2007, the SC Newsletter has become one of the major activities of the Student Consortium with 32 issues published in softcopy. A subset of those issues was also distributed to participants at ISPRS related events in hardcopy with the principal financial support of the ISPRS Council. In the last four-year period, 13 issues were published and three more issues are planned to be published before the ISPRS Congress in Prague. Three of these 13 issues were distributed at the ISPRS summer schools organized in Indonesia, Ethiopia, Myanmar, China and the Philippines (see Figure 11). These issues were prepared with regards to the topics of the related summer schools. The hardcopy issues have a special place among the rest not only because they need more elaborative work but also due to their real-time influence and positive feedback ending up in more people realizing the power of the $\mathrm{SC}$ and thus joining in as members.

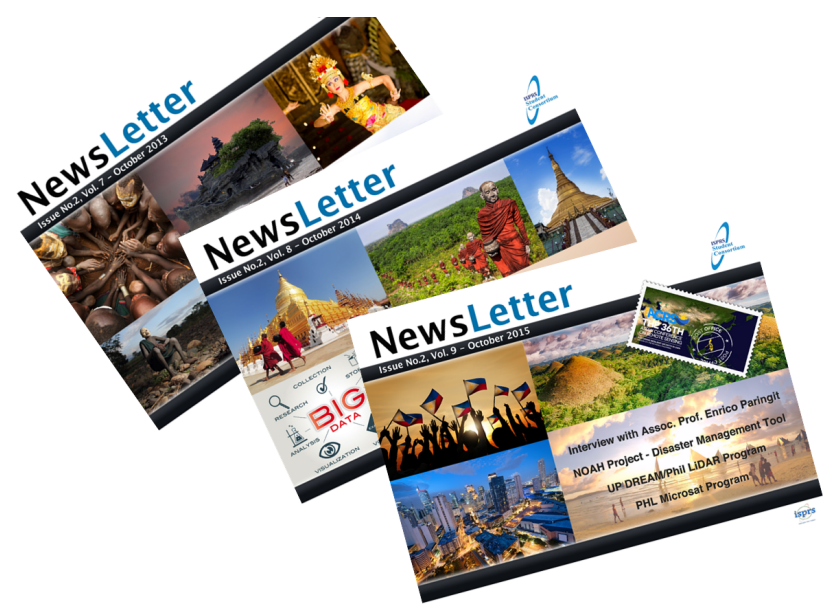

Figure 11. Various cover designs of the SC Newsletter that were distributed at summer schools.

There was one special issue topic, published in two parts as Vol. 7, No. 3 and No. 4, dedicated to women in science and engineering. Since the fields of photogrammetry, remote sensing, and the geospatial sciences are still strongly dominated by men, these special topic issues encouraged the female members of the SC to publish their work. These two dedicated issues took a lot of interest from both the contributors and the newsletter readers (see Figure 12).

Taking in consideration the interest in these special topic issues there will be another special topic double issue published before the ISPRS Congress in Prague. This time the topic will be on free and/or open source software that could be used for research or studies by young scientists and students. 


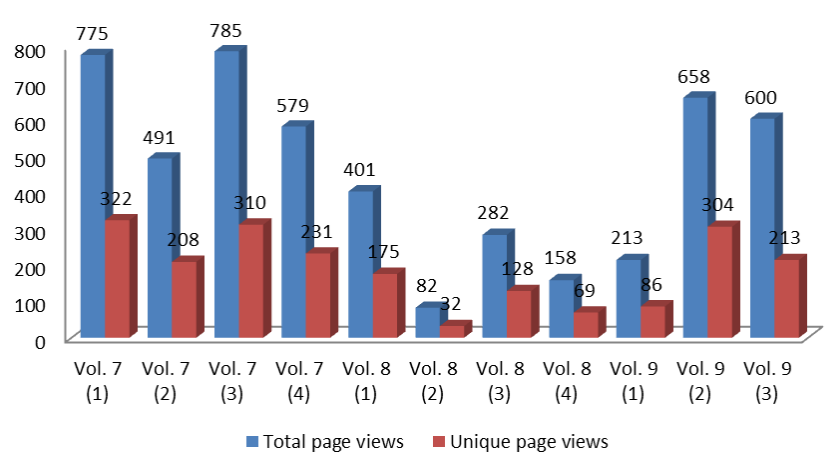

Figure 12. Statistics of the SC Newsletter page visits since April 17, 2013 (since the publication of Vol. 7, No. 1).

Joining the ISPRS SC is a great avenue of integration into the ISPRS. Additionally, the SC Newsletter is a great opportunity for students and young professionals to publish articles about their work and research as well as to stay informed about job and scholarship opportunities, upcoming SC related events and other interesting activities (Kivilcim et al., 2012).

\subsection{Website}

The SC website (http://www.isprs-sc.org/) was established in 2009 for the internet-based dissemination and for sharing information about SC events (e.g., workshops and summer schools), opportunities for scholarships and jobs, and archives of published materials (e.g., the newsletters and course materials for the summer schools). In addition to the online information and materials, people who have an interest in the ISPRS Student Consortium including students and professionals can register as members by providing some basic information on the website. The membership registration is linked to an email service provided by MailChimp (http://mailchimp.com/; described in subsection 3.5.1).

During the mandate of the current board members (2012-2016), there were a few improvements with the website:

1.) Facebook buttons such as "Like" and "Share" were made functional on the announcement and information pages;

2.) Google analytics was installed to collect access logs and analyse access trends for better insights on the information dissemination (Figure 13); and

3.) Minor typos were corrected, layout adjustments were made, and malfunctioning hyperlinks were fixed.

There were attempts to replace the current system with Drupal (http://www.drupal.org/), the most popular content management system (CMS) used for web administration. The required functions and appearances of the new system were discussed among the board members and some volunteers, and then documented for possible implementation. Although the new Drupal-based system was expected to enable better content management for more dynamic and attractive pages, it could not be launched because it needed much more effort than expected in transferring the database of the current system to the database of the new system. This problem may have to be addressed by the next SC board members.

\subsection{Social media outreach}

In addition to the Student Consortium Newsletter and website, there exist a number of social media outlets, which serve as platforms for information exchange between the members of the organization. The SC maintains a MailChimp e-mail list, Flickr photo albums, a Facebook public group page, and Twitter and LinkedIn accounts.

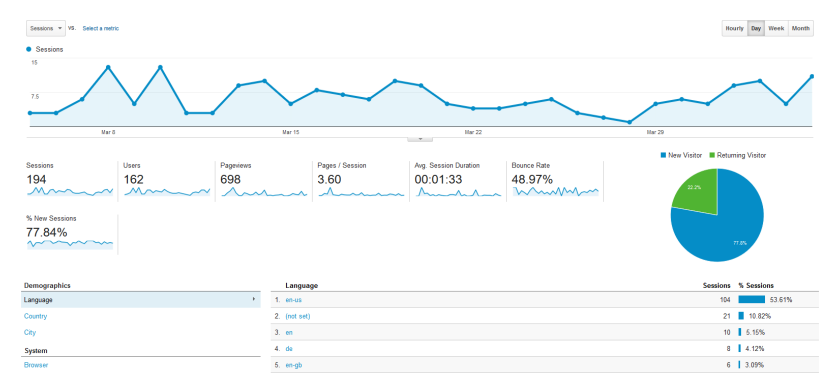

Figure 13. Dashboard of Google Analytics for the website.

\subsubsection{Mailing list}

Since 2012, the ISPRS Student Consortium has been using the MailChimp mass e-mail service to send out announcements to its users. Announcements include links to newly published newsletter issues, reminders about submission deadlines for conferences, and information about ISPRS student-related events such as summer schools, and opportunities for travel funding. The mailing list currently contains 1,104 subscribers with an average of $23 \%$ "opens" and $5.5 \%$ "clicks". In the last two years, the "opens" ranged from $24 \%$ to $26 \%$, which is substantially higher than the "industry" average of $16 \%$. The MailChimp service is not ideal for the SC as it is provided by a third party, which is different than the provider for the website and the e-mail address of the organization. One issue is that the website membership and the MailChimp mailing list cannot be perfectly synchronized as users of the e-mail service can subscribe or unsubscribe at any time, which cannot be automatically reflected in the membership list. However, the MailChimp service only takes minimal maintenance, and it is free for the current number of Student Consortium subscribers.

\subsubsection{Flickr}

The ISPRS Student Consortium has a Flickr account, where anybody can browse through the photo albums of the organization and download any posted photos. The photos included in the albums are from ISPRS student-related events such as summer schools and conferences. The account was initiated in 2009 . There currently are 245 total photos organized in eleven albums. The ISPRS SC Flickr albums can be seen at:

\section{- https://www.flickr.com/photos/42199570@N03/sets}

\subsubsection{Facebook}

The ISPRS Student Consortium public group page on Facebook was launched in 2011. It was started so that SC members can freely interact with one another by posting job openings, opportunities for graduate studies, scholarships, and studentrelated event dates. While it is the most informal communication media for the society, it is also the most active one. Prior to the XXII ISPRS Congress in Melbourne, Australia in 2012 the public Facebook page had approximately 350 members (Kivilcim et al., 2012), while prior to the 2014 midterm symposium in Wuhan, China it had 2,528 members (Kanjir et al., 2014). The page currently has 4,610 members, which is a 13 -fold increase in the last four years, and a $180 \%$ increase in the last two years. The Web address for the Facebook page is:

- https://www.facebook.com/groups/isprssc/.

\subsubsection{Twitter and LinkedIn}

The Twitter and LinkedIn accounts for the ISPRS Student Consortium were started in June 2012, before the Melbourne congress. Prior to the last mid-term symposium, there were 43 
followers on Twitter and 63 members on LinkedIn (Kanjir et al., 2014). At the time of writing of this paper (i.e., April 2016), there are 153 followers on Twitter and 118 LinkedIn members. The Twitter followers more than tripled and the LinkedIn ones almost doubled in the last two years. While the absolute numbers cannot compare to the members on the Facebook public page, the stated increases still show solid growth. The Twitter and LinkedIn Web addresses can be found at:

- https://twitter.com/isprs_sc

- https://www.linkedin.com/groups/4510838

\section{STRATEGIC PLAN FOR THE FUTURE}

Building on its current activities the Student Consortium should focus its future work on the following topics/issues:

1.) Bring the current website up to contemporary standards, i.e., it needs to be more dynamic and visually attractive.

2.) Recruit new members for the society. For example, continue expanding in Africa, and encourage membership growth in Latin America (e.g., Brazil) and Eastern Europe (e.g., the Russian Federation). This could be done through public debates during conferences or through organizing summer schools in these regions.

3.) Restructure the SC board and reduce the duration of certain SC board positions. These modifications will bring more balance in terms of the work load for the involved board members, and allow for more flexibility in both their appointment and resignation. Any changes made should be included in the SC statutes.

4.) Engage coordinators to promote the Student Consortium locally. Coordinators should have permanent positions (e.g., university instructors or professors) so that the network could be introduced to a constant flux of young professionals.

5.) The organization should seek collaboration with student bodies from other interdisciplinary societies in order to complement its interests and gain more knowledge about related disciplines. Examples could be the International Geodetic Student Organization (IGSO) in Europe, the Student Advisory Council (SAC) part of the American Society for Photogrammetry and Remote Sensing (ASPRS), the Young Surveyors Network part of the International Federation of Surveyors (FIG).

6.) Document procedures and archive reports on various $\mathrm{SC}$ engagements and activities in order to evaluate the current status of the organization and to help in planning the future work of the society. This would also smoothen any transitions between SC board members. New SC board members could learning from the experiences of the previous members and they would not have to "reinvent the wheel."

7.) Conduct a survey in order to obtain knowledge about the current needs of the new generation of SC members. Likewise, get constructive feedback from student participants in summer schools and conferences in order to assist with the modification of current and the design of new activities.

8.) Replace the word "student" in the name of the society, so graduate-level and post-doctoral researchers from any country would be comfortable joining. Likewise, rename the SC Newsletter as to encourage a larger volume of serious technical contributions.
Apart from the mentioned recommendations, the organization should strengthen further professional development opportunities for young professionals and continue to serve as a platform for information exchange.

\section{CONCLUSIONS}

The purpose of this paper was to review the Student Consortium activities in the last four years. The $\mathrm{SC}$ has become more diverse in terms of its international membership pool (and its representation on the board), the locations of the organized events and the general outlook of the society. With its activities the organization aims at strengthening the education and training experience for all young professionals no matter the stage of their career or background. A proof that the society has made visible progress and that it has had great impact on its members can be seen in its strong recognition over social media. For example, the activity of members and number of career opportunities for individuals on our social media platforms are constantly increasing.

It could be concluded that the progress and accomplishments achieved by the organization thus far are due to the careful planning of its current and past leadership. However, a lot has to still be done in the future to keep the society strong. The next four-year mandate will be an exciting time for the new board members and the members of the Student Consortium in general. The SC should continue to be a platform for inspiration, information exchange and networking between its members. Let us join efforts to make the Student Consortium an even better society - one which is respected world-wide and one of which the ISPRS should be proud of.

\section{ACKNOWLEDGEMENTS}

The Student Consortium board would like to acknowledge the ISPRS Council for financially supporting the organization since the beginning of its existence. The board would also like to thank all the past and present volunteers who have contributed to the organization by committing time and effort in order for the Student Consortium members to have valuable experiences.

\section{REFERENCES}

Baltsavias, E., 2005, Student Activities within ISPRS. ISPRS Highlights, Vol. 10, No. 3, pp. 7.

Dowman, I., Kufoniyi, O., 2010. Policies for applying Earth observation in Africa: An ISPRS perspective. The International Archives of the Photogrammetry, Remote Sensing and Spatial Information Sciences, Kyoto, Japan, Vol. XXXVIII, Part 8, pp. 1088-1093.

Kanjir, U., Detchev, I., Reyes, S. R., Akkartal, A. A., Lo, C. Y., Miyazaki, H., 2014, ISPRS Student Consortium: From launch to tenth anniversary. The International Archives of the Photogrammetry, Remote Sensing and Spatial Information Sciences, Vol. XL, Part 6, pp. 43-48, ISPRS Technical Commission VI Symposium, May 19-21, Wuhan, China.

Kivilcim, C. O., 2008, Proceedings of the ISPRS Student Consortium: Participation of the Youth for a Sustainable 
Society. The International Archives of the Photogrammetry, Remote Sensing and Spatial Information Sciences, Vol. XXXVII, Part B6a, Beijing, China.

Kivilcim, C. O., Sterenczak, K., Kanjir, U., Sengul, A., Stavbar, G., Pakdil, M. E., Lobo, E., Oo, K.S., 2010, ISPRS Student Consortium Mid-term Status Report (2008-2010). The International Archives of the Photogrammetry, Remote Sensing and Spatial Information Sciences, Vol. XXXVIII, Part 6, ISPRS Technical Commission VI Symposium, June 2-4, Enschede, The Netherlands.

Kivilcim, C. O., Sterenczak, K., Kanjir, U., Sengul, A., Stavbar, G., Pakdil, M. E., Lobo, E., Oo, K.S., 2012, ISPRS Student Consortium: The network of youth in geoinformation society. The International Archives of the Photogrammetry, Remote Sensing and Spatial Information Sciences, Vol. XXXIX-B6, XXII ISPRS Congress, Aug 25-Sept 1, Melbourne, Australia. 